\title{
Sensorless Motor Drives with Predictive Current Control
}

\author{
${ }^{1}$ Simi P.B, ${ }^{2}$ C.Harini, ${ }^{3}$ Dr. Hari Krishna Prasad . P \\ ${ }^{I}\left(\right.$ PG student CMRCET), ${ }^{2}$ (Asst.Prof.CMRCET) ${ }^{3}$ (Prof.CMRCET,B.tech(EEE)2000,M.tech(PE)2002)
}

\begin{abstract}
Hardware complexity of a motor drive can be reduced by estimating controls rather than measuring using sensors. In this way the corresponding sensors are eliminated and the system becomes more robust. This article is about speed control of a sensor less induction motor with predictive current controller technique. This particular speed control technique does not require direct measurements of motor speed or motor flux. The PCC is based on a closed loop observer, which is insensitive to parameter variations. This closed loop observer calculates the required state variables over wide frequency range. This technique is more reliable even at very low frequency due to its insensitive nature against changes of motor parameters. It is proved that the drive system is applicable to the high dynamic performance and wide range of rotor speed. The obtained simulation results confirm the good properties of the proposed speed sensor less induction motor drive.
\end{abstract}

Keywords- predictive current control, closed loop observer, sensorless induction motor.

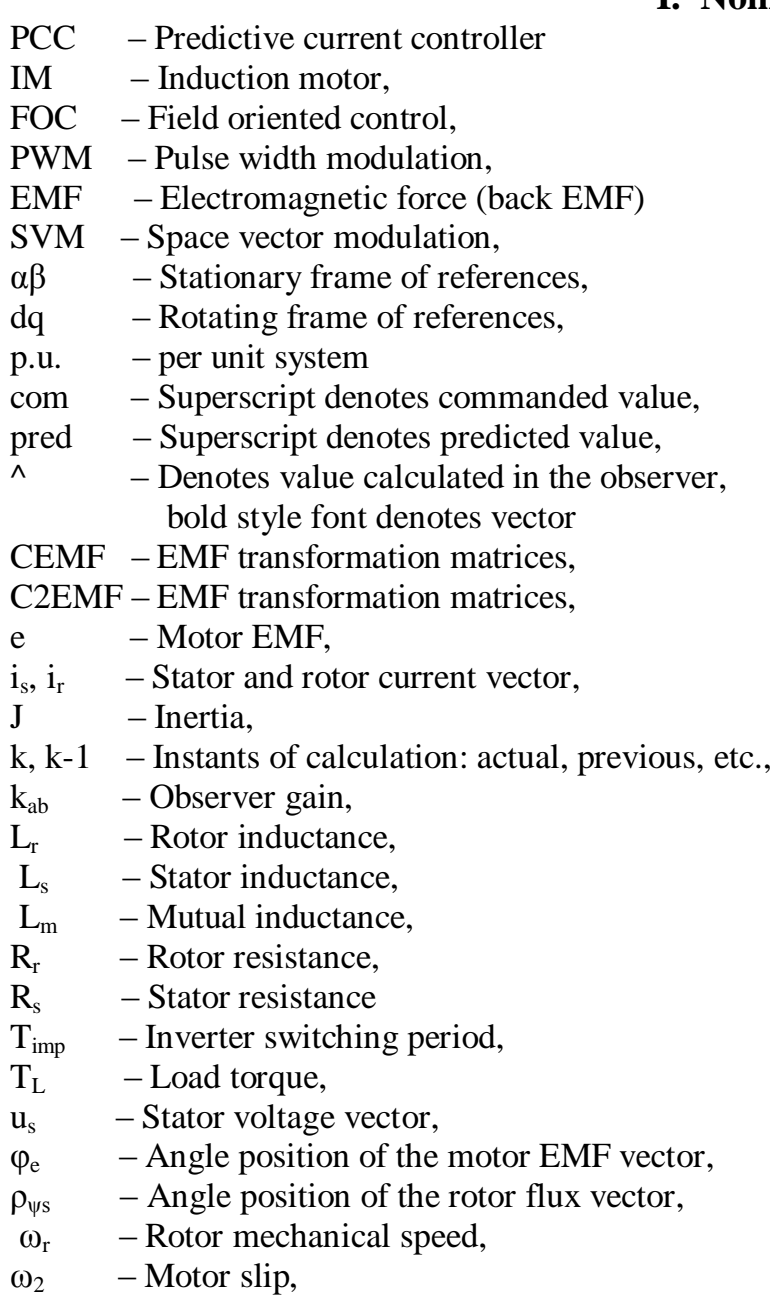

\section{Introduction}

Induction motors are ideal for most industrial and commercial applications and are widely used. A continuous trend in induction motor is to improve the reliability of the system. One solution is to decrease the number of sensors being used. ie most modern induction motor sensor elimination is required. 
On going research were concentrated on the elimination of speed sensor at the machine shaft without detoriating dynamic performance of the drive system. If we remove sensors we will get some advantages like low cost, reduced size, elimination of sensor cable etc In sensorless induction motor we are not measuring the actual speed, the same will be extracted from the measured stator voltage and current at the motor terminal. The calculated values will have some non-linearities.For overcoming these non-linearities and to get good dynamic response predictive current control is implemented.

In AC-drive systems, fast current and torque responses are necessary. The development of high performance controls for AC-machine drives has motivated considerable attention in recent years. Many studies are reported for current controls.

The main objective of the current control is to ensure the tracking of the desired stator currents in a transient interval as short as possible. There are different strategies for current controllers. The main ones are linear control, hysteresis control, and predictive control. Among them, a widely used scheme for high performance is the predictive control.

For more than 20 years the field oriented control is state of- the-art in industrial drive applications, though first ideas of predictive control have already been proposed in the 60s. After a more "silent" period in the following decade, many fundamental predictive control systems like Direct Torque Control (DTC), Predictive Current Control appeared during the 80s. More methods have been invented to control the armature current of DC-machines connected to a line-commutated converter. Since DC-drives have lost their importance in applications with dynamic requirements more and more, these paper only deals with predictive control structures concerning inverter supplied AC-machines.

In this paper PCC is implemented in the IM speed sensorless system with field oriented control method. One of the mature control systems of induction motor is the field oriented control method. The FOC method is widely used and presents some high standards in modern industrial drives. In the FOC system instead of linear PI current controllers, predictive current controllers may be used. The current control algorithm previously presented [6] was modified by using the observer system instead of simple load model .With such approach, better results were recorded. To avoid the system complication for the PCC, the back EMF calculation was integrated to flux and speed observer for FOC IM drive.

\section{The Basic Scheme For The Foc}

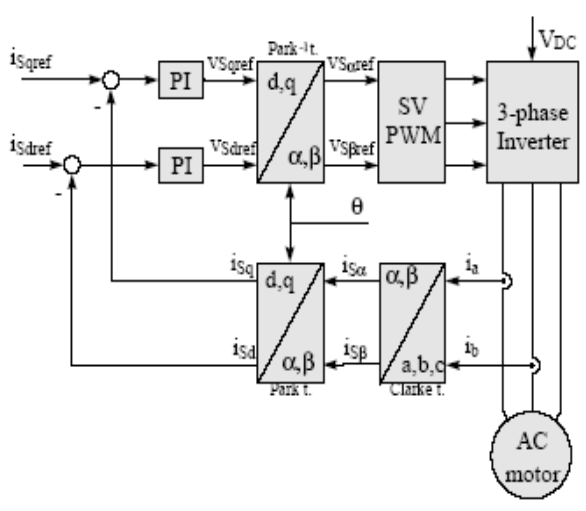

Figure1: Basic scheme of FOC for AC-motor

Two motor phase currents are measured. These measurements feed the Clarke transformation module. The outputs of this projection are designated $i_{s \alpha}$ and $i_{s \beta}$. These two components of the current are the inputs of the Park transformation that gives the current in the $d, q$ rotating reference frame. The $i_{\text {Sd }}$ and $i_{\text {Sq }}$ components are compared to the references $i_{\text {Sdref }}$ (the flux reference) and $i_{\text {Sqref }}$ (the torque reference). At this point, this control structure shows an interesting advantage: it can be used to control either synchronous or induction machines by simply changing the flux reference and obtaining rotor flux position. As in synchronous permanent magnet motors, the rotor flux is fixed (determined by the magnets) there is no need to create one.

Hence, when controlling a PMSM, $\mathrm{i}_{\text {Sdref }}$ should be set to zero. As induction motors need a rotor flux creation in order to operate, the flux reference must not be zero. This conveniently solves one of the major drawbacks of the "classic" control structures: the portability from asynchronous to synchronous drives. The torque command $i_{\text {Sqref }}$ could be the output of the speed regulator when we use a speed FOC. The outputs of the current regulators are $\mathrm{v}_{\text {Sdref }}$ and $\mathrm{v}_{\text {Sqref; }}$; they are applied to the inverse Park transformation. The outputs of this projection are $\mathrm{v}_{\mathrm{saref}}$ and $\mathrm{v}_{\mathrm{s} \beta \mathrm{ref}}$ which are the components of the stator vector voltage in the $\alpha, \beta$ stationary orthogonal reference frame. These are the inputs of the Space Vector PWM. The outputs of this block are the signals that drive the inverter. Note that both Park and inverse Park transformations need the rotor flux position. 
Obtaining this rotor flux position rotor flux position depends on the AC machine type (synchronous or asynchronous machine).

\section{Proposed System}

The structure of the proposed system is presented in Fig. 2.

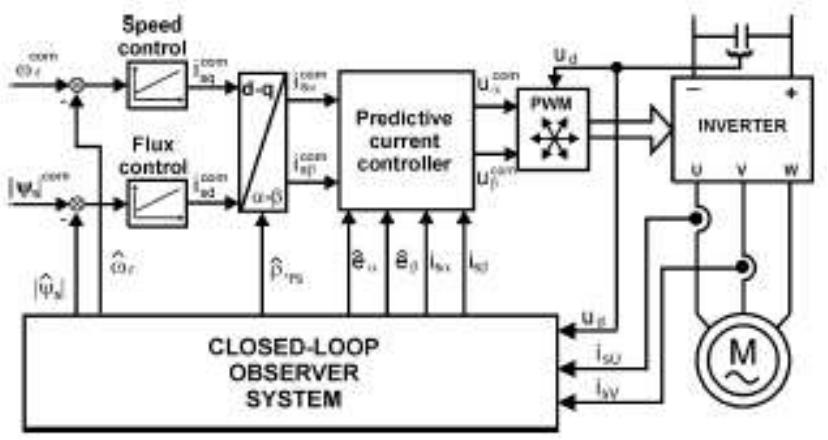

Fig. 2. Structure of the proposed speed sensorless field oriented control with closed-loop observer and predictive current controller.[1]

The stator field oriented control method is used in the drive. The superior PI controllers regulate the motor speed and rotor flux. The commanded motor current is $\mathrm{i}_{\mathrm{s}}{ }^{\mathrm{com}}$ transformed from dq to $\alpha \beta$ coordinates. The PCC controls the motor stator current in $\alpha \beta$ coordinates. Calculations of the PCC are synchronized with PWM algorithm used for the inverter output voltage generation. The inverter with PWM and PCC works as controlled current source. The system works without speed sensor, while only the inverter input voltage and output currents are measured by hall-effect sensors. Other variables required by control system are calculated in closedloop observer system.

\section{A. Closed Loop Observer System}

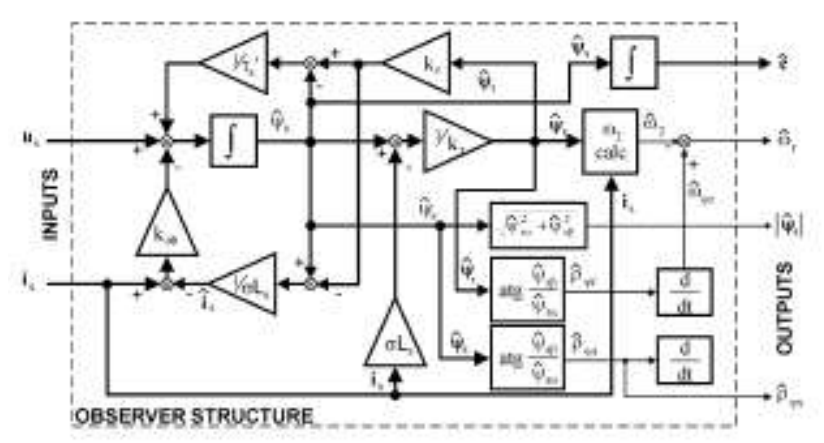

Fig. 3. Structure of the closed-loop observer.

Closed loop observer system [1] is based up on the voltage model of an induction motor with the combination of rotor and stator fluxes. In this the whole control does not need the measurement of motor speed and flux. The required rotor flux and motor speed by the controllers are calculated in the observer, simultaneously motor emf is calculated for the use in predictive current controller feedback,ie the state variables are calculated by the observer system by using only the command value of stator voltage and the measured stator current and de link voltage. approach.

In this project a closed loop observer with robustness against parameter variation is used for the control

Input to the observer system are Stator voltage and Stator current Output from the observer system are Rotor mechanical speed, Stator flux, Angle position of the stator flux vector, Back emf for the use in PCC .

Two commonly used methods of flux estimation are Voltage model and Current model . In this project voltage model is used in this method the machine terminal voltages and currents are sensed and fluxes are computed from the stationary frame $\left(\alpha^{\mathrm{s}}, \beta^{\mathrm{s}}\right)$.from the equivalent circuit of induction machine in stationary reference frame.

$$
\begin{aligned}
\psi_{\alpha s} & =\int\left(V_{\alpha s}-R_{s} i_{\alpha s}\right) d t \\
\psi_{\beta s} & =\int\left(V_{\beta s}-R_{s} i_{\beta s}\right) d t
\end{aligned}
$$




$$
\left|\psi_{\mathrm{s}}^{\wedge}\right|=\sqrt{ }\left(\psi^{\wedge}{ }_{a s}{ }^{2}+\psi_{\beta s_{s}}{ }^{2}\right)
$$

Equations(1) and (2)has the advantage that motor speed information is not required for the flux calculation.

Rotor flux estimation is done by doing further calculations and by knowing the values of stator fluxes, we can calculate the rotor fluxes.

$$
\begin{aligned}
& \psi_{a r}=\mathrm{L}_{\mathrm{r}} / \mathrm{L}_{\mathrm{m}}\left(\psi_{\mathrm{as}}-\sigma \mathrm{L}_{\mathrm{s}} \mathrm{i}_{\alpha \mathrm{s}}\right) \\
& \psi_{\beta \mathrm{r}}=\mathrm{L}_{\mathrm{r}} / \mathrm{L}_{\mathrm{m}}\left(\psi_{\beta \mathrm{s}}-\sigma \mathrm{L}_{\mathrm{s}} \mathrm{i}_{\beta \mathrm{s}}\right) \\
& \psi^{\wedge}=\left(\psi_{\mathrm{r}}^{\wedge}{ }_{\mathrm{s}-} \sigma \mathrm{L}_{\mathrm{s}} \mathrm{i}_{\mathrm{s}}\right) / \mathrm{k}_{\mathrm{r}} \\
& \sigma=1-\mathrm{L}_{\mathrm{m}}{ }^{2} / \mathrm{L}_{\mathrm{r}} \mathrm{L}_{\mathrm{s},} \mathrm{k}_{\mathrm{r}=} \mathrm{L}_{\mathrm{m}} / \mathrm{L}_{\mathrm{r} .}
\end{aligned}
$$

where

Sensorless vector control of an induction drive essentially means vector control without any speed sensor. An incremental shaft-mounted speed encoder is required for closed loop speed or position control in both vector and scalar controlled drives.It is possible to estimate the speed signal from machine terminal voltage and currents with the help of DSP. However the estimation is highly complex and heavily dependent on machine parameters. The parameter variation near zero speed imposes a challenge in the accuracy of speed estimation.

In induction motor there are different methods of speed estimation like 1) Slip calculation ,2) Direct synthesis from state equation,3) MRAS,4) Speed adaptive flux observer,5) Extended kalman filter etc.The closed loop observer used in this project uses the method direct synthesis from state equations for the calculation of speed. In this project voltage model is used in this method the machine terminal voltages and currents are sensed and fluxes are computed from the stationary frame $\left(\alpha^{\mathrm{s}}, \beta^{\mathrm{s}}\right)$.from the equivalent circuit of induction machine in stationary reference frame.

By knowing the values of rotor fluxes in $\alpha$ and $\beta$ co-ordinates position of rotor flux can be obtained as

$$
\hat{\rho} \psi_{\mathrm{r}}=\operatorname{arctg}\left(\psi_{\mathrm{r} \beta} / \hat{\psi}_{\mathrm{r} \alpha}\right)
$$

Rotor mechanical speed is obtained from the difference between rotor flux synchronous speed and slip speed. Rotor mechanical speed $=$ Rotor flux synchronous speed - Slip speed

where

$$
\hat{\omega_{\mathrm{r}}}=\hat{\omega}_{\psi \mathrm{r}}-\hat{\omega}_{2}
$$

$\omega_{\psi}^{\wedge}={ }_{\mathrm{rd}} \hat{\rho} \psi_{\mathrm{r}} / \mathrm{d} \tau$

Then

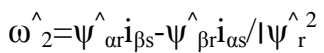

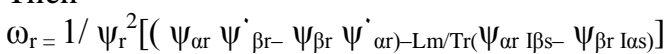

From the equation of speed obtained(11) it is clear that speed can be estimated from the stator voltage and current and also by using the rotor flux from the observer.

By knowing the values of stator and rotor flux we can estimate the stator current. The estimated current will be different from what we given as input because $i_{s}$ is the last measured sample and $i_{s}{ }^{\wedge}$ is the estimated value for next step of operation.

$$
\begin{aligned}
& \mathrm{i}_{\mathrm{s}}=\left(\hat{\psi_{\mathrm{s}}}-\mathrm{K}_{\mathrm{r}} \psi_{\mathrm{r}}{ }_{\mathrm{r}}\right) /\left(\sigma \mathrm{L}_{\mathrm{s}}\right) \\
& \mathrm{e}^{\wedge}=\mathrm{d} \psi \hat{\mathrm{s}} \mathrm{s} / \mathrm{d} \tau
\end{aligned}
$$

This emf is being used for further calculation in the predictive current controller.If we notice the speed equations from the observer, the parameters appearing in the observer are the motor inductance and the stator resistance. However the closed loop observer used in sensorless induction motor has robustness against parameter variations. When the parameter values are changed from its nominal value there won't be any effect.

The motor parameters appearing in the observer are the motor inductances and the stator resistance. The inductances have little effect on the performance, while the stator resistance has a small effect at frequencies close to zero. The presented flux and speed observer has proved to be highly insensitive against stator resistance mismatch. This significantly extends the stable operating region even without parameter tuning. Rotor resistance is not included in the observer system, so it has no noticeable effect on it; however it is included in slip calculation. 


\section{B. PREDICTIVE CURRENT CONTROLLER}

PCC is an approach to estimate induction motor speed from measured terminal voltage and currents for speed-sensor less motor control. It is based on the computation of backemf by the closed loop observer. The technique is simple, robust to variations of motor parameters due to operating conditions. This approach is not dependent upon the knowledge of the stator resistance, nor is affected by stator resistance thermal variations. The basis of this thesis is the development and implementation of a predictive current controller.

The basics of the predictive controller are the simplified Thevenin circuit for an induction machine. For derivation purpose induction motor was modeled as an inductance and an emf connected in series, while the small motor resistance is neglected. The control process involves estimation of back-emf and estimation of inductance.

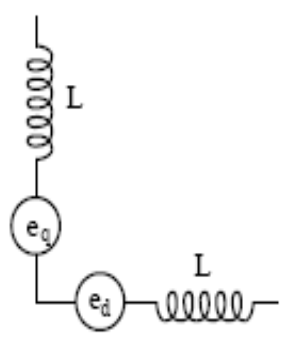

Fig4.The two-phase equivalent induction machine model

In order to use the two-phase model shown in Figure4 to determine control voltages, it is necessary to know the model back-emf. On each control interval, the back-emf must be estimated from the past behavior of the model.

$$
\mathrm{V}_{\mathrm{k}}-\mathrm{e}_{\mathrm{k}}=\mathrm{L}_{\mathrm{l}} / \mathrm{T}\left(\mathrm{i}_{\mathrm{k}}-\mathrm{i}_{\mathrm{k}-1}\right)
$$

The aim of the controller is to determine the inverter voltage $v_{k+1}$ required to achieve the set point current $\mathrm{u}_{\mathrm{k}+1}$ on each cycle. For constant frequency PWM, it is necessary to know the voltage at the start of the switching cycle. This is because the output must switch immediately from the zero vector at the start of the cycle if the maximum voltage is required.

As the current measurement at the end of the previous cycle $\left(i_{k}\right)$ is not available until after the next has started, this measurement cannot be used in the control calculation. Instead this value is estimated from the previous measurements of the current. Because of the symmetric switching pattern, the average applied voltage is the same over the second half of the switching cycle as over the first half. For a constant back-emf, the change in current over each of the halves of control interval is the same according to the e -1 model.

The predictive control algorithm involves first estimating the model parameters. This is done from past measurements. The model is then used to determine the voltage necessary to meet the control objective for each control interval. Using discrete-time notation, where $i *$ is the current at the midpoint, a set of estimation and control equations are:

$$
\begin{aligned}
& \mathrm{e}_{\mathrm{k}}{ }^{\text {est }}=\mathrm{v}_{\mathrm{k}}-2 \mathrm{~L}_{\mathrm{l}} / \mathrm{T}\left(\mathrm{i}^{*}{ }_{\mathrm{k}}-\mathrm{i}_{\mathrm{k}-1}\right) \\
& \mathrm{V}_{\mathrm{k}+1}=\mathrm{e}_{\mathrm{k}+1}{ }^{\text {est }}+\mathrm{L}_{\mathrm{l}} / \mathrm{T}\left(\mathrm{i}_{\mathrm{k}+1}-2{ }{ }_{\mathrm{k}}+\mathrm{i}_{\mathrm{k}-1}\right)
\end{aligned}
$$

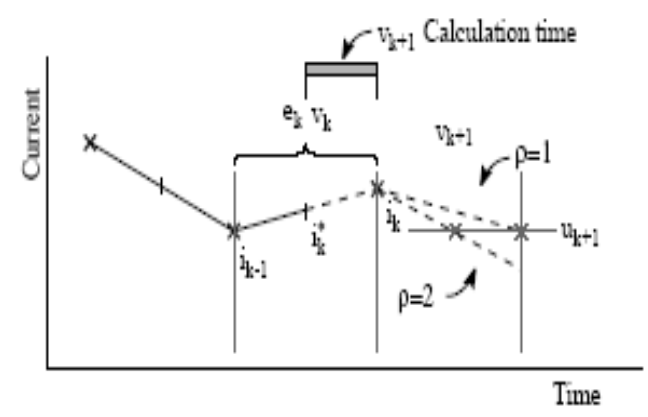

Figure 5: The variables used in the controller

The controller developed using these equations was able to successfully control the machine current, but the bandwidth was affected by the delay in the back-emf estimate. For typical operating conditions, an error of up to $4 \%$ can be expected in the current tracking.

Here EMF was calculated using the simple equation of the IM model. In this paper, the accuracy of EMF calculation is improved. Better accuracy of EMF calculation is obtained using flux and speed closed-loop 
observer presented in the previous section. The observer structure is extended in order to calculate the EMF simultaneously with flux and speed computation. So in PCC the EMF calculation part is removed and substituted by the signals obtained directly from the observer system. [1]

Stator current dynamic system is described by:

$$
\mathrm{di}_{\mathrm{s}} / \mathrm{dt}=\left(\mathrm{u}_{\mathrm{s}}{ }^{\mathrm{com}}-\mathrm{e}\right) /\left(\sigma \mathrm{L}_{\mathrm{s}}\right)
$$

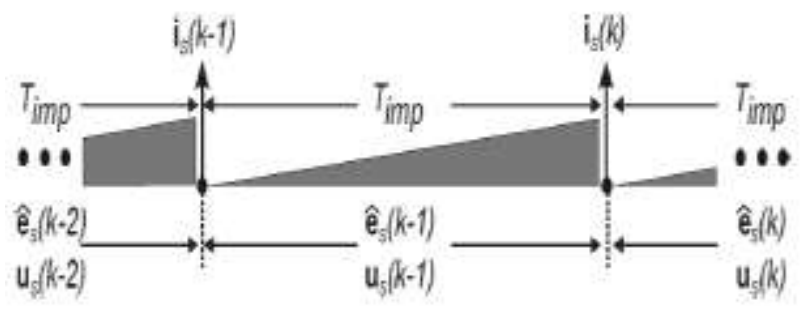

Fig.6: Used notation in PCC for switching periods.

Assuming the notation presented in Fig. 6 and for small $\mathrm{T}_{\text {imp }}$ it is possible to convert (17) to the next discrete form:

$$
\left[i_{5}(k)-i_{5}(k-1)\right] / T_{\text {ing }}=\left[u_{5}^{\cos }(k-1)-e(k-1) f\left(\sigma L_{5}\right)\right.
$$

Considering (17) for period (k-1)..(k) the known values are: commanded voltage $\mathrm{u}_{\mathrm{s}}^{\text {com }}(\mathrm{k}-1)$ and measured current $i_{s}(k-1)$. Other variables as $i_{s}(k)$ and $e(k-1)$ are unknown and should be predicted. The EMF value e(k-1) was simply predicted based on known samples of $\mathrm{e}(\mathrm{k}-2)$ and $\mathrm{e}(\mathrm{k}-3)$ as follows:

$$
\begin{aligned}
& \hat{e}(\mathrm{k}-2)=\sigma \mathrm{L}_{5}\left(\mathbf{i}_{5}(\mathrm{k}-2)-\mathrm{i}_{5}(\mathrm{k}-1)\right) / \mathrm{T}_{\mathrm{imp}}+\mathbf{u}_{5}^{\cos }(\mathrm{k}-2) \\
& \hat{e}(\mathrm{k}-3)=\sigma \mathrm{L}_{5}\left(\mathbf{i}_{5}(\mathrm{k}-3)-\mathbf{i}_{5}(\mathrm{k}-2)\right) / \mathrm{T}_{\mathrm{iwp}}+\mathbf{u}_{5}^{\cos }(\mathrm{k}-3)
\end{aligned}
$$

In this thesis instead of (20)-(21) the EMF is calculated in the flux and speed observer according to (18). The samples of $\mathrm{e}^{\wedge}(\mathrm{k}-2)$ and $\mathrm{e}^{\wedge}(\mathrm{k}-3)$ calculated by the observer are memorized and used in the successive calculations.

The change of position of the EMF vector is

$$
\Delta \varphi_{e}[(k-2),(k-3)]=\Delta \varphi_{e}=\varphi_{e}(k-2)-\varphi_{e}(k-3)(21)
$$

The calculations of (21) require two arc tangent calculations for obtaining $\varphi_{e}(\mathrm{k}-1)$ and $\varphi_{e}(\mathrm{k}-2)$. To simplify (21) calculation of trigonometric relation with only one arc tangent function is used:

$$
\Delta \varphi_{\mathrm{e}}=\mathrm{a} \tan \frac{\hat{e}_{\alpha}(\mathrm{k}-2) \hat{e}_{\beta}(\mathrm{k}-3)-\hat{e}_{\alpha}(\mathrm{k}-3) \hat{e}_{\beta}(\mathrm{k}-3)}{\hat{\mathrm{e}}_{\alpha}(\mathrm{k}-2) \hat{e}_{\alpha}(\mathrm{k}-3)+\hat{e}_{\beta}(\mathrm{k}-2) \hat{e}_{\beta}(\mathrm{k}-3)}
$$

In the IM the EMF speed changes slowly so for small $\mathrm{T}_{\mathrm{imp}}$ it is possible to predict $\mathrm{e}^{\wedge}(\mathrm{k}-1)$ by rotating $E M F$ vector with small $\Delta \varphi_{\mathrm{e}}$ angle calculated by (22).

The predicted value of $\mathrm{e}^{\wedge}(\mathrm{k}-1)$ is:

$$
\begin{gathered}
\mathrm{e}^{\text {pred }}(\mathrm{k}-1)=\mathrm{C}_{\mathrm{EMF}} \hat{e}(\mathrm{k}-2) \\
\mathrm{C}_{\mathrm{EMF}}=\left[\begin{array}{cc}
\cos \left(\Delta \varphi_{\mathrm{e}}\right) & \sin \left(\Delta \varphi_{\mathrm{e}}\right) \\
-\sin \left(\Delta \varphi_{\mathrm{e}}\right) & \cos \left(\Delta \varphi_{\mathrm{e}}\right)
\end{array}\right]
\end{gathered}
$$

The IM stator current sample at instant $(\mathrm{k})$ is predicted[1]

$$
i_{5}^{\text {pred }}(k)=i_{5}(k-1)+\left[u_{5}^{\operatorname{com}}(k-1)-e^{\text {pred }}(k-1)\right) \int_{i m p} /\left(\sigma L_{5}\right)
$$

To optimize PCC action the minimization of current regulation error was chosen as cost function. The current regulation error at instant $(\mathrm{k}-1)$ and $(\mathrm{k})$ is as follows:

$$
\begin{aligned}
& \Delta \mathbf{i}_{\mathrm{s}}(\mathrm{k}-1)=\mathbf{i}_{\mathrm{s}}^{\operatorname{com}}(\mathrm{k}-1)-\mathbf{i}_{\mathrm{s}}(\mathrm{k}-1) \quad(26) \\
& \Delta \mathbf{i}_{\mathrm{s}}(\mathrm{k})=\mathbf{i}_{\mathrm{s}}^{\cot }(\mathrm{k})-\mathrm{i}_{\mathrm{s}}^{\operatorname{prod}}(\mathrm{k})
\end{aligned}
$$

In [6] the next controller function was used:

$$
\mathrm{u}_{\mathrm{s}}^{\cos }(\mathrm{k})=\sigma \mathrm{L}_{\mathrm{s}} \mathrm{s}_{5}^{\cos }(\mathrm{k}+1)-\mathrm{i}_{\mathrm{s}}^{\mathrm{pred}}(\mathrm{k})+\mathrm{D}_{\mathrm{Is}} \mid \mathrm{T}_{\mathrm{inep}}+\mathrm{e}^{\operatorname{pred}}(\mathrm{k})
$$


The voltage vector $\mathrm{u}_{\mathrm{s}}{ }^{\text {com }}(\mathrm{k})$ calculated with (28) is applied to the minimize stator current regulation error at $(\mathrm{k}+1)$. Equation (23) is based on (11) with addition of correction part $\mathrm{D}_{\mathrm{Is}}$ :

$$
\begin{gathered}
\mathrm{D}_{\mathrm{Is}}=\mathrm{W}_{1} \mathrm{C}_{\mathrm{EMF}} \Delta \mathrm{i}_{\mathrm{s}}(\mathrm{k})+\mathrm{W}_{2} \mathrm{C}_{2 \mathrm{EMF}} \Delta \mathbf{i}_{5}(\mathrm{k}-1) \\
\mathrm{e}^{\mathrm{prod}}(\mathrm{k})=\mathrm{C}_{2 \mathrm{EMF}} \mathrm{e}(\mathrm{k}-2) \\
\mathrm{C}_{2 \mathrm{EMF}}=\left[\begin{array}{cc}
\cos \left(2 \Delta \varphi_{\mathrm{e}}\right) & \sin \left(2 \Delta \varphi_{\mathrm{e}}\right) \\
-\sin \left(2 \Delta \varphi_{\mathrm{e}}\right) & \cos \left(2 \Delta \varphi_{\mathrm{e}}\right)
\end{array}\right]
\end{gathered}
$$

The controller coefficients $\mathrm{W} 1$ and $\mathrm{W} 2$ are tuned to minimize regulation error.

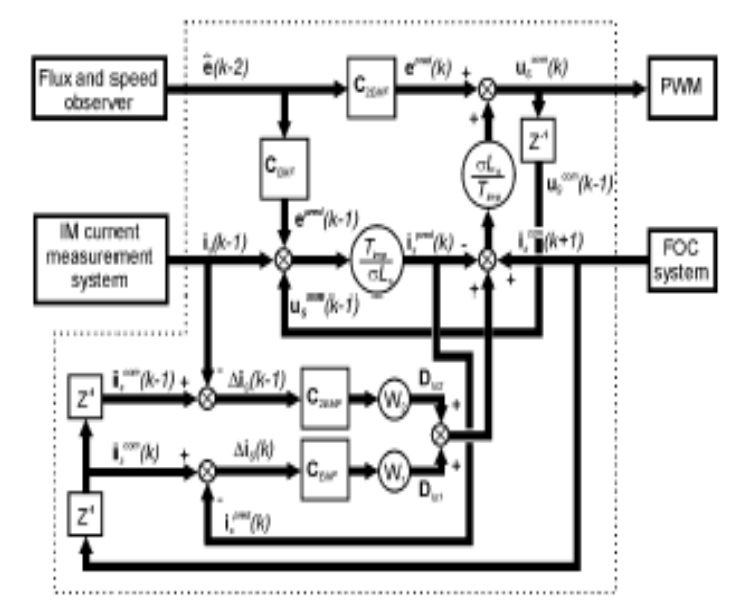

Figure 7: Predictive current controller structure[1]

\section{Experimental Results}

The experimental results are presented in Fig. 8 to Fig. 12.

Firstly the results for speed sensorless of the proposed FOC IM drive are presented.

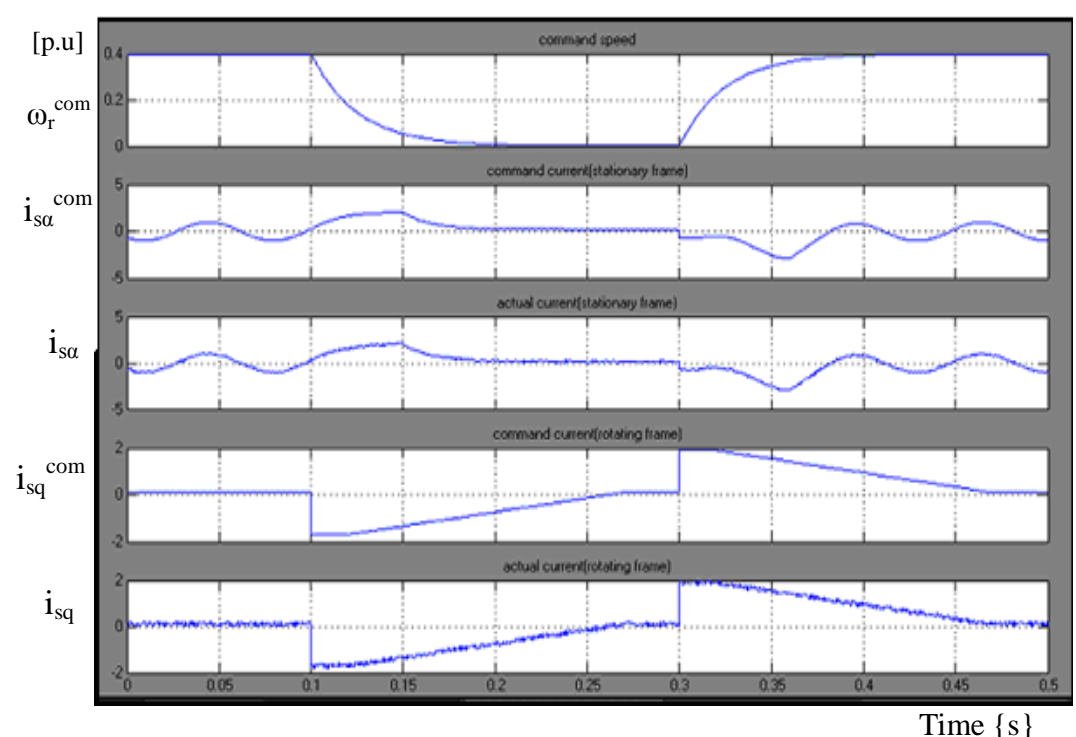

Fig. 8.Sensorless operation - motor current control in $\alpha \beta$ and dq references during commanded speed changes

In Fig. 8 motor speed changes are commanded - decreasing and increasing. The waveforms of the current present consistency between commanded and actual currents components. Proper work of the whole system is noticeable. 


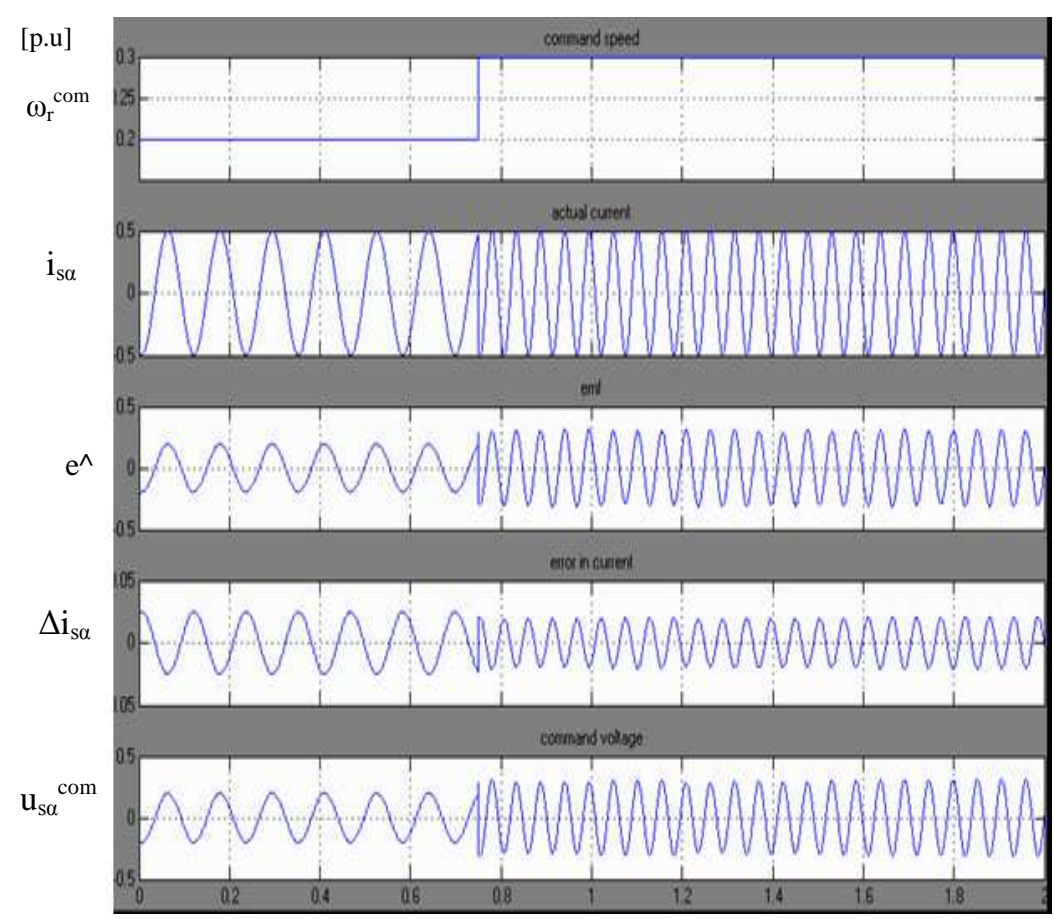

Fig. 9. Step change of motor frequency related to $\omega r$

Time $\{\mathrm{s}\}$ $20 \%$ to $30 \%$ of the motor rated mechanical speed.

The speed is being first increased to $20 \%$ of rated speed(1740rpm) and then to $1885 \mathrm{rpm}$. the corresponding changes in actual current, estimated emf, command value of voltage in $\alpha$-coordinate and error in current estimation are shown ,from the graph it is clear that error I is always obtained at a minimum level, ie up to the $3 \%$ level.

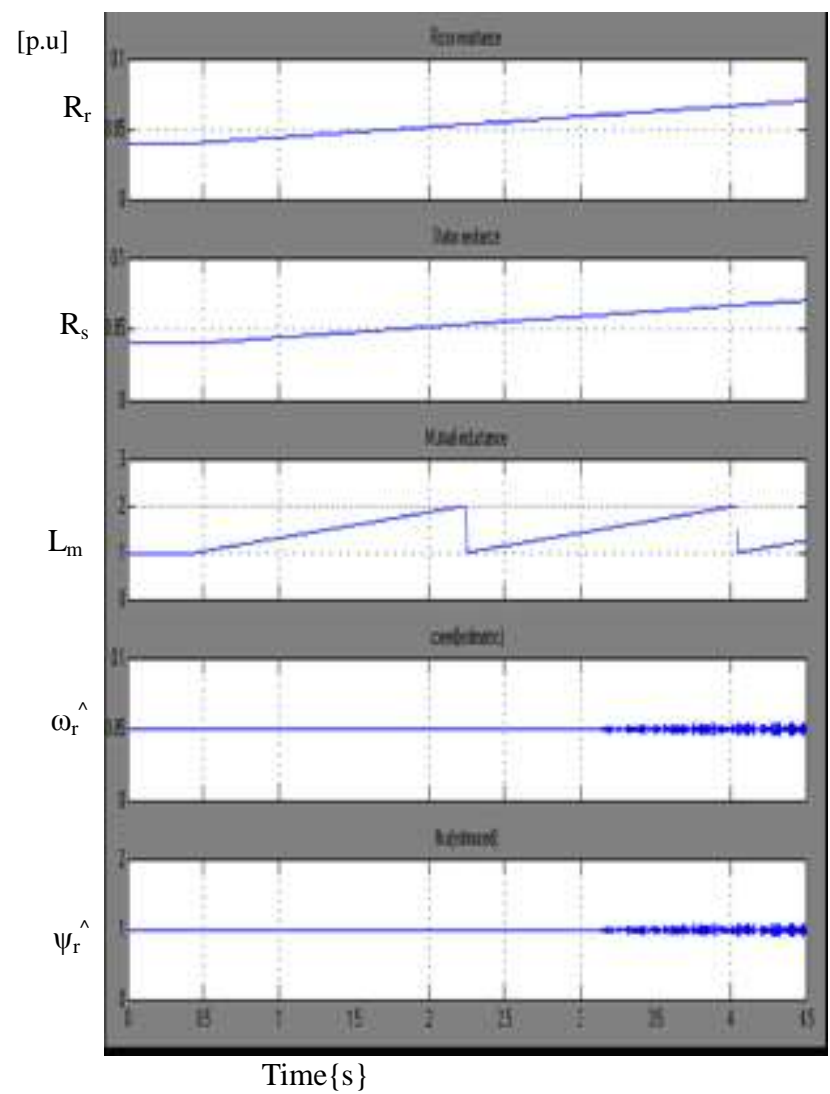

Fig. 10. Response of the system for the simultaneously changes of motor parameters (runs at $5 \%$ of rated speed) - for $t>3 \mathrm{~s}$ system is unstable (the result of high simultaneous parameters changes). Nominal par. are in Tab. I. 
The robustness on motor parameters changes is presented in fig.10.where a simultaneous rotor and stator resistances as well mutual inductance, used in the observer and PCC, are changed. The test shows motor operation with extreme deviations of the motor parameters. The varied parameters were lower as well as greater than initial nominal parameters. Nominal values are shown in Table 1.In spite of changes, the system maintains stability. Only after very high and simultaneous changes of all parameters, the system starts to work unstably for time $>3 \mathrm{~s}$.If the parameter $\mathrm{s}$ variations are limited to values which can practically appear in the real motor the drive can work prolonged properly.

The fig. 11 shows the operation condition under motor load for $10 \%$ of rated motor speed reversing. The motor speed has been reduced to 1305rpm,then the actual speed follows the reference after taking some time for stabilization. we can also observe that the current regulation error is under 3\%. This shows the proper working of the proposed system. The system also passes the regenerative mode of operation successfully.

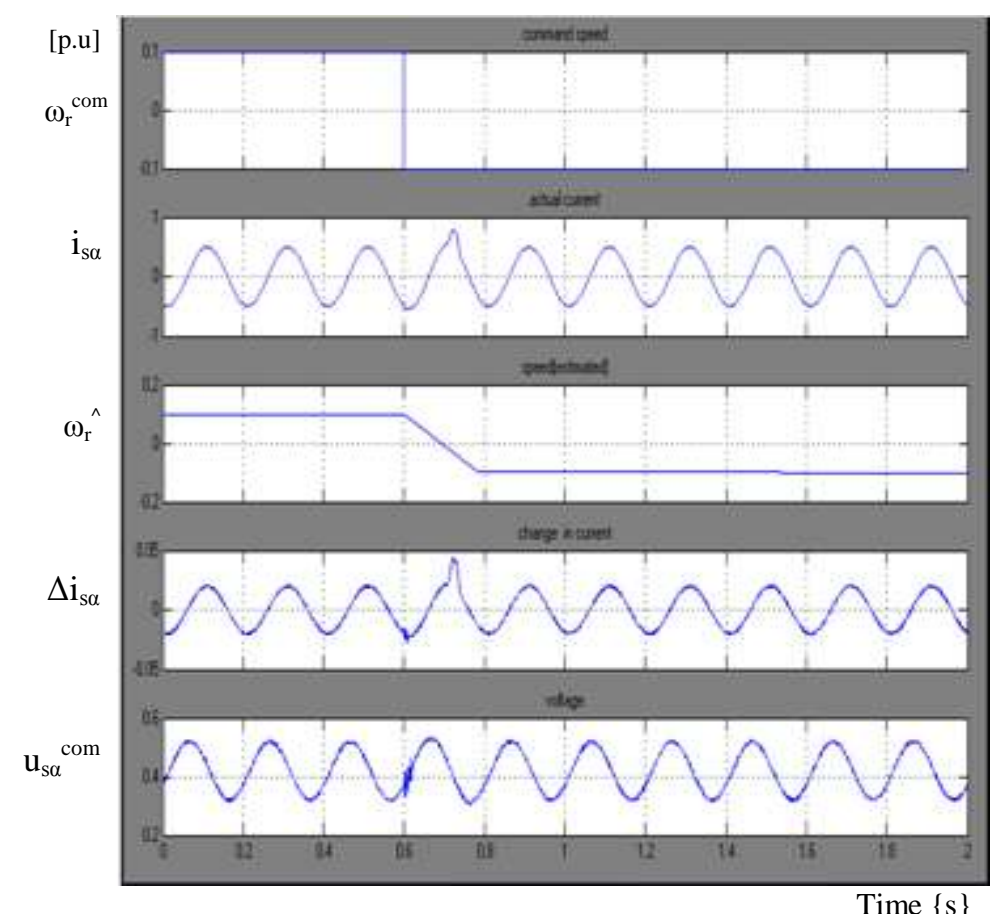

Fig.11. Motor reversing from $10 \%$ to $-10 \%$ of rated speed under load.

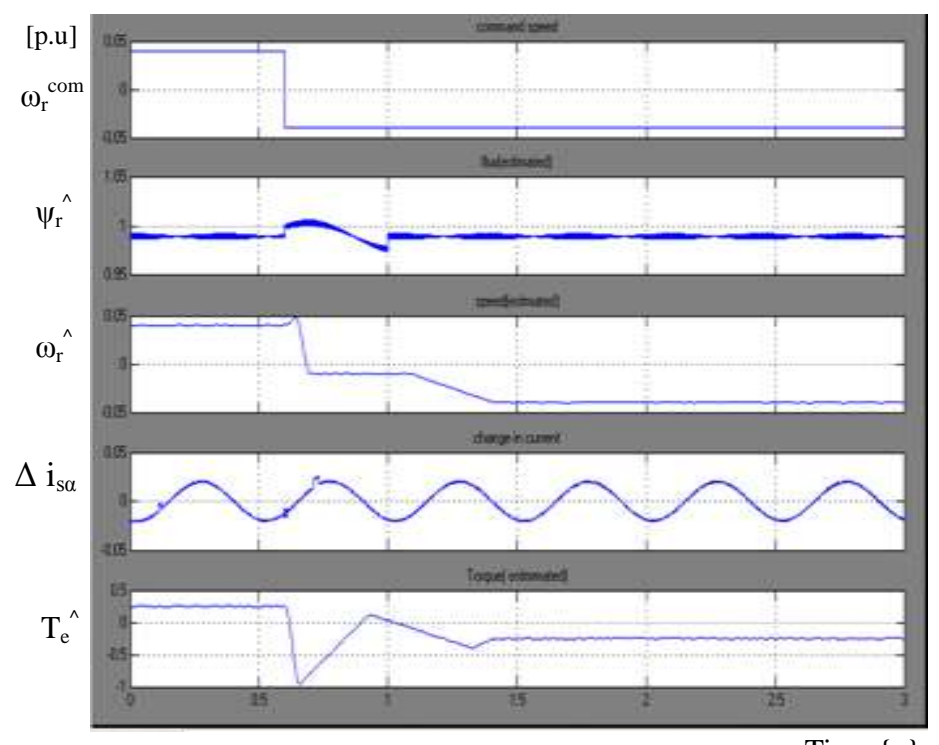

Time $\{s\}$

Fig. 12. Motor reversing from $4 \%$ to $-4 \%$ of rated speed under load. 
The motor reverse from 4\%(60rpm) of normal speed is done. The system passes the regenerative mode of operation successfully.

\section{Conclusions}

Low speed sensorless control of induction motor with the predictive current controller is simulated. Accuracy of calculation is improved since PCC is based on the computation of back EMF by the observer. All state variables are calculated by the observer system which is practically insensitive to inaccuracy of calculations and the deviation of motor parameters. The simulation results confirm the dynamic performance of the proposed speed sensorless IM drive. The proposed IM drive works correctly even at very low speed.

TABLE I

\begin{tabular}{c|c|c}
\multicolumn{3}{c}{ TABLE I } \\
\hline Parameter & Value & Description \\
\hline$P_{N}$ & $55 \mathrm{~kW}$ & Nominal power \\
\hline$U_{N}$ & $3 \times 400 \mathrm{~V} 50 \mathrm{~Hz}$ & Nominal voltage \\
\hline$I_{s}$ & $11 \mathrm{~A}$ & Nominal curreut \\
\hline$n_{s}$ & $1450 \mathrm{mpm}$ & Nominal speed \\
\hline$J$ & $0.029 \mathrm{kgm}$ & Inertia \\
\hline$R_{r}$ & $1 \Omega(0.48 \mathrm{pu})$ & Stator resistance \\
\hline$R_{r}$ & $1.07 \Omega(0.48 \mathrm{pu})$ & Rotor resistance \\
\hline$L_{\mathrm{x}}$ & $215 \mathrm{mH}(1.606 \mathrm{pu})$ & Mutual inchuctance \\
\hline$L_{n}$ & $220 \mathrm{mH}(1.65 \mathrm{lpu})$ & Stator inductance \\
\hline$L_{r}$ & $220 \mathrm{mH}(1.651 \mathrm{pu})$ & Rotor inchuctance \\
\hline
\end{tabular}

\section{References}

[1] Jaroslaw: Guzinski, Gdansk University of Technology, Haitham Abu-Rub: Texas A\&M University at Qatar "Predictive Current Control Implementation in the Sensorless Induction Motor Drive ",IEEE 2011

[2\} R. Kennel, A. Linder, "Predictive Control of Inverter Supplied Electrical Drives," in IEEE 31st Annual Power Electronics Specialists Conference, PESC 2000, vol. 2, 18-23 June 2000, Galway, Ireland.

[3]. Jaroslaw Guzinski, Haitham Abu-Rub, "Preditive Current Control Implementation in Sensorless Induction Motor Drive"IEEE transactions on power electronics, November , 2011

[4] B. K. Bose, Modern Power Electronics and AC Control, PTR, 2002

[5] Joachim Holtz,Junato Quan ,'Sensorless Vector Conrol of IM at Very Low Speed using a Nonlinear Inverter Model." IEEE transactions on industial applicatiines. , Vol.38, No.4 ,Jul-Aug 2002.

[6] Jean-marie Retif, Xuefang Lin-Shi,Florent Morel,"Preditive Current Control for an Induction Motor"in 21 avenue jean capelle 69621 Villeurbann Cedex,France,2008

[7] P. Vas, Vector Control of AC Machines. Clarendon Press, Oxford University Press (Oxford [England], New York) 1990.

[8] J. Rodriguez, J. Pontt, C. Silva, M. Salgado, S. Rees, U. Ammann, P. Lezana, R. Huerta, P. Cortes, "Predictive control of threephase inverter," IEEE Electronic Letters, 29th April 2004 Vol. 40 No. 9.

[9] H. Abu-Rub, N. Oikonomou, "Sensorless Observer System for Induction Motor Control," in 39th IEEE Power Electronics Specialists Conference, PESC 2008. 15-19 June 2008, Rhodes, Greece.

[10] H. Abu-Rub, J. Guziński, J. Rodriguez, R. Kennel, P. Cortés P., "Predictive current controller for sensorless induction motor drive," in IEEE-ICIT 2010 International Conference on Industrial Technology, 14-17 March 2010, Viña del Mar, Chile.

[11] J. Salomäki, M. Hinkkanen, J. Luomi, "Sensorless vector control of an induction motor fed by a PWM inverter through an output LC filter," IEEE Trans. on Industrial Electronics, vol. 126-D, no. 4, Apr. 2006.

[12] J. Guzinski, "Sensorless AC drive control with LC filter," in $13^{\text {th }}$ European Conference on Power Electronics and Applications EPE 2009. 8-10 September 2009r. Barcelona, Spain. 